\title{
Malaria and the climate in Karachi: An eight year review
}

\author{
Fivzia Herekar ${ }^{1}$, Sundus Iftikhar ${ }^{2}$ \\ Ahsana Nazish ${ }^{3}$, Sabeen Rehman ${ }^{4}$
}

\begin{abstract}
Background and Objective: Malaria is an arthropod-borne infectious disease transmitted by the mosquito Anopheles and claims millions of lives globally every year. Reasons for failure to eradicate this disease are multifactorial. The seasonality of the malaria is principally determined by climatic factors conducive for breeding of the vector. We aimed to study the relationship between climatic variability and the seasonality of malaria over an eight-year duration.

Methods: This was a retrospective medical chart review of 8,844 confirmed cases of malaria which presented to The Indus Hospital, Karachi from January 2008 to November 2015. Cases were plotted against meteorological data for Karachi to elicit monthly variation.

Results: A secular incline and seasonality in malaria cases over the duration of eight years was seen. More cases were reported in the summer, rainy season compared with the other three seasons in each year. There was significant association with specific climate variables such as temperature, moisture, and humidity.

Conclusion: There is a marked seasonal variation of malaria in Karachi, influenced by various environmental factors. Identification of the 'the concentrated period' of malaria can be helpful for policymakers to deploy malaria control interventions.
\end{abstract}

KEYWORDS: Anopheles, Malaria, Seasonality.

doi: https://doi.org/10.12669/pjms.36.ICON-Suppl.1712

How to cite this:

Herekar F, Iftikhar S, Nazish A, Rehman S. Malaria and the climate in Karachi: An eight year review. Pak J Med Sci. Special Supplement ICON 2020. 2020;36(1):S33-S37. doi: https://doi.org/10.12669/pjms.36.ICON-Suppl.1712

This is an Open Access article distributed under the terms of the Creative Commons Attribution License (http://creativecommons.org/licenses/by/3.0), which permits unrestricted use, distribution, and reproduction in any medium, provided the original work is properly cited.

1. Fivzia Herekar, FCPS (Infectious Diseases), Department of Internal Medicine,

2. Sundus Iftikhar, Mphil (Statistics),

3. Ahsana Nazish, MSc (Health Policy and Management), Malaria Program,

4. Sabeen Rehman, FCPS (Internal Medicine), Department of Internal Medicine,

1-4: Indus Hospital Research Center,

The Indus Hospital,

Karachi, Pakistan.

Correspondence:

Dr. Fivzia Herekar, Department of Internal Medicine, The Indus Hospital,

Karachi, Pakistan.

Email: fivzia.herekar@tih.org.pk

* Received for Publication:

* Accepted for Publication:

August 3, 2019

November 15, 2019

\section{INTRODUCTION}

Over one billion vector-borne diseases occur annually, with more than a million deaths from malaria, dengue, chikungunya and yellow fever, making up to $17 \%$ of infectious diseases. ${ }^{1}$ Amongst multiple vectors; the most well-known is the mosquito, responsible for malaria along with dengue, chikungunya, yellow fever, zika, West Nile fever and Japanese encephalitis. Malaria is a high burden yet preventable disease. It is still endemic in the WHO regions of Africa, South-East Asia and the Eastern Mediterranean. Despite declining incidence since 2000, cases in 2015 were still a staggering 214 million with estimated deaths of $438000 .^{2}$ One million cases were reported from Pakistan that year despite 
decreasing trends between 2010 to 2015, when 400,000 fewer cases of malaria annually were seen from previous years. ${ }^{3}$

The malarial parasite requires the female Anopheles mosquito to complete its life cycle before transmission back to the human. There are 430 types of Anopheles mosquito and 3040 transmit malaria. ${ }^{4}$ Of 38 species identified in Pakistan, ${ }^{5}$ Anopheles subpictus, Anopheles culicifaciens, and Anopheles stephensi are most prevalent. ${ }^{6}$ They breed in turbid, waterlogged areas and animal ponds rich in inorganic matter and fauna. Its life cycle is completed within the mosquito in 10-18 days, when the vector must survive in the environment. Environmental factors thus have an important role in transmission. The climatic factors most conducive to survival of the malarial parasite are rainfall, a temperature of 16$18^{\circ} \mathrm{C}$ and humidity levels of $55-80 \% .^{7-10}$

Globalization, unplanned urbanization, global warming and agricultural reforms has led to deforestation and irrigation projects, creating ideal breeding sites for mosquitoes. Studying the seasonal peaks of diseases caused by mosquitoes and the impact of climate on their life cycle will help predict and map areas and seasons of high burden. In addition, programmatic steps, such as establishing case definition, diagnosis, steps for treatment and prevention, can be incorporated, targeting seasonal variations of the disease burden to achieve better overall disease control.

\section{METHODS}

A retrospective medical chart review was conducted at Indus Hospital, Karachi (TIH). Appropriate ethical approvals were in place (IRB no. IRD_IRB_2015_08_004). All confirmed cases of malaria presenting to TIH from January 2008 until November 2015 were included in the study. The incidence of malaria was recorded per month and compared to various meteorological indices for the same period. Meteorological data included daily maximum, minimum, and mean temperatures, humidity, dew point, wind speed, and precipitation. Information was downloaded from Weather Underground, where data is crowd-sourced by global environmental sensors and air pollution monitors. Data for the aformentioned variables was accessed from the closest station to TIH, i.e. Jinnah International Airport, Karachi (http:// www.wunderground.com/history / airport / OPKC/2015/3/15/DailyHistory.html?\&reqdb. zip $=\&$ reqdb. magic $=\&$ reqdb.wmo=).
Statistical analysis: Data was analysed using Eviews 9 software. Partial correlation was assessed between malaria cases and climate variables adjusting for years. Cameron and Trivedi test was applied to assess the over-dispersion assumption of Poisson regression. The Negative Binomial regression was used because Poisson regression demonstrated an insignificant P-value $(<0.05)$ despite a negative slope coefficient, demonstrating the latter regression method was inappropriate for this dataset. Pearson correlation was applied to assess the association between various climate variables. In addition, co-integration between variables was assessed using Johnson co-integrated test. Johnson co-integrated test includes trace and maximum Eigen values test to assess co-integration. These two tests reported 5 co-integrated equations showing that the variables were co-integrated.

The lag length for climate variables was selected using lag length criteria using the sequential modified likelihood ratio (LR) test statistic, final prediction error (FPE), Akaike information criterion (AIC), Schwarz information criterion (SC) and Hannan-Quinn information criterion (HQ). However, all the aforementioned criteria indicated different lag lengths. Models on several lag lengths were therefore built ( 1 to 7 -the maximum lag length selected by various lag selection criterion).

All the climate variables with low or no multicollinearity were included in the model. Their lag values were included in the multiple Negative Binomial regression models. The final model was selected based on the Akaike Information Criterion (AIC). The model with minimum AIC and HQ value was chosen as the final model. Model with lag (1) was found to have minimum AIC and HQ values.

\section{RESULTS}

A total of 8,944 malaria cases were reported over eight years with minimum cases reported in $2008(\mathrm{n}=96)$ and maximum in $2014(\mathrm{n}=2,625$, Fig.1), showing a secular incline and seasonality in malaria cases. Of the total cases, 4730 (53\%) had species identified and the most prevalent was plasmodium vivax $96.6 \%$, the remainder comprised of mixed infection and Plasmodium falciparum.

There are four seasons in Pakistan: a cool, dry winter (December to February), a hot dry spring (March to May), the summer monsoon season (June 


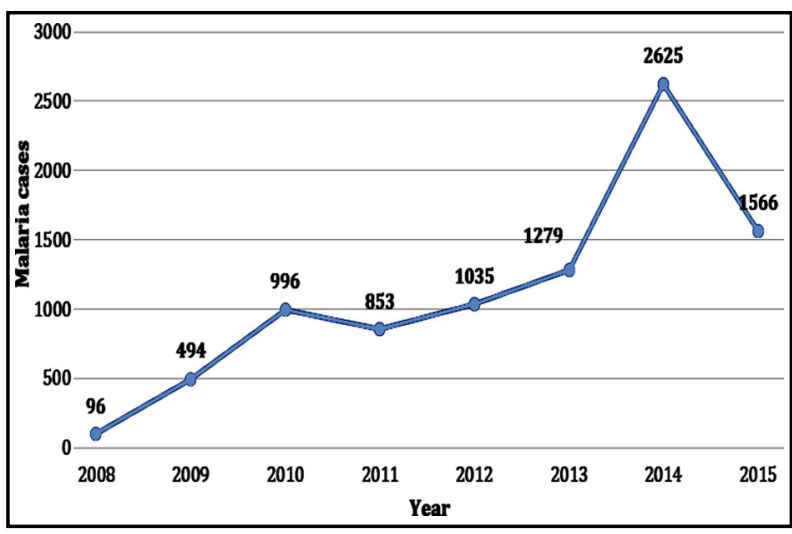

Fig.1: Annual malaria cases at TIH, Pakistan, 2008-2015.

to September) and the retreating monsoon period (October and November). ${ }^{11}$ Malaria cases were reported more frequently in the summer rainy season as compared to the other three seasons in each year (Fig.1 and 2, Table-I) with peaks from June to October.

The maximal humidity in Karachi was in August (86.3\%), with a minimal temperature of $32.7^{\circ} \mathrm{C}$, leading to a high number of cases in September i.e. with a lag of one month. Malaria cases were significantly associated with various climate variables (Table-II). A substantial positive correlation with mean temperature (0.658, $\mathrm{p}<0.0001)$, mean dew point $(0.687, \mathrm{p}<0.0001)$ and mean humidity $(0.65, \mathrm{p}<0.0001)$ was seen. Moreover, moderately positive correlation was found between mean wind speed $(0.583, \mathrm{p}<0.05)$, wind direction degrees $(0.516, \mathrm{p}<0.05)$ and cloud

Table-I: Month-wise distribution of malaria cases at TIH across 2008 to 2015. (SD=standard deviation)

\begin{tabular}{lccc}
\hline \multirow{2}{*}{ Months } & \multirow{2}{*}{$\begin{array}{c}\text { Number } \\
\text { of months }\end{array}$} & \multicolumn{2}{c}{ Malaria Cases } \\
\cline { 3 - 4 } & 8 & $15.8(11.9)$ & $0-34$ \\
Jan & 8 & $15.6(12.6)$ & $0-36$ \\
Feb & 8 & $29.6(25.6)$ & $1-74$ \\
Mar & 8 & $55.1(45)$ & $0-136$ \\
Apr & 8 & $119(127.7)$ & $3-399$ \\
May & 8 & $161.4(139.3)$ & $8-429$ \\
Jun & 8 & $112.8(72.4)$ & $12-240$ \\
Jul & 8 & $166.1(117.4)$ & $19-395$ \\
Aug & 8 & $196.8(126.2)$ & $24-409$ \\
Sep & 8 & $156.8(79.5)$ & $16-293$ \\
Oct & 8 & $68.6(47.3)$ & $8-147$ \\
Nov & 7 & $23.4(12.3)$ & $5-40$ \\
Dec & &
\end{tabular}

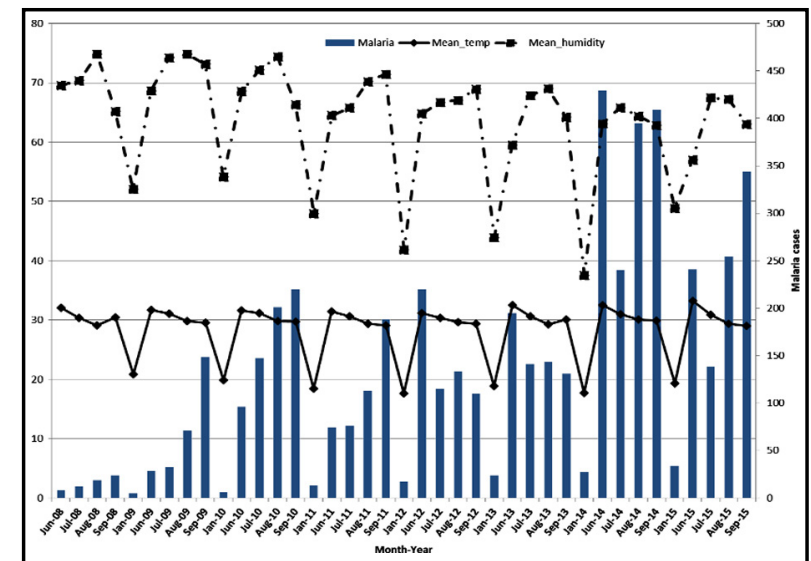

Fig.2: Relation of monthly malaria cases with temperature and humidity.

cover $(0.433, \mathrm{p}<0.05)$. A negative but strong correlation with mean sea level pressure $(-0.639$, $\mathrm{p}<0.0001$ ) was also seen.

Data from 2015 revealed it was the hottest year in the past decade in Karachi. On average, the temperature of Karachi remains between $34^{\circ} \mathrm{C}$ to $36^{\circ} \mathrm{C}$ due to sea breeze but in June 2015 the temperature rose to $45^{\circ} \mathrm{C}$ and humidity dropped from $70 \%$ to $12 \%{ }^{12,13}$ Notably, the incidence of malaria was low in this year.

The incidence of malaria depended on humidity levels in the preceding month (Equation-1, Fig.2). The multiple negative binomial regression model suggested that if the humidity level was a unit higher in one month, cases will experience a statistically significant rise in the following month (Coeff: 0.0777, p=0.000, Equation-I). The year (trend) variable, shows visually the significantly positive effect on malaria cases, supporting secular incline in malaria cases (Equation-I). Also notable is the decline in malaria cases in 2015 related to the preceding month humidity.

Equation-I: Negative binomial regression model.

$\log ($ Malaria $)=$ intercept $+a^{*} \operatorname{lag}$ (mean humidity) $+b^{*}$ trend

$\log ($ Malaria $)=-1.853+0.0777 * \operatorname{lag}$

(mean humidity) +0.0399 *trend (AIC: 10.2$)$

$(\mathrm{P}$-value $=0.0080)$

$(\mathrm{P}$-value $=0.000)$

$(\mathrm{P}$-value $=0.000)$

\section{DISCUSSION}

Karachi is located along the Arabian coast and is the largest city of Pakistan. It experiences moderately high temperatures with high humidity. ${ }^{14}$ The rapidly increasing population 
Fivzia Herekar et al.

Table-II: Partial correlation of malaria cases with climate variables (adjusted for years).

\begin{tabular}{llll}
\hline Climate variables & Partial correlation & Climate variables & $\begin{array}{c}\text { Partial } \\
\text { correlation }\end{array}$ \\
\hline Max Temperature $\left({ }^{\circ} \mathrm{C}\right)$ & $0.592^{* *}$ & Mean Sea Level Pressure $(\mathrm{hPa})$ & $-0.639^{* *}$ \\
Mean Temperature $\left({ }^{\circ} \mathrm{C}\right)$ & $0.658^{* *}$ & Min Sea Level Pressure $(\mathrm{hPa})$ & $-0.635^{* *}$ \\
Min Temperature $\left({ }^{\circ} \mathrm{C}\right)$ & $0.672^{* *}$ & Max Visibility $(\mathrm{Km})$ & -0.199 \\
Max Dew Point $\left({ }^{\circ} \mathrm{C}\right)$ & $0.674^{* *}$ & Mean Visibility $(\mathrm{Km})$ & 0.29 \\
Mean Dew Point $\left({ }^{\circ} \mathrm{C}\right)$ & $0.687^{* *}$ & Min Visibility $(\mathrm{Km})$ & 0.00 \\
Min Dew point $\left({ }^{\circ} \mathrm{C}\right)$ & $0.697^{* *}$ & Max Wind Speed $(\mathrm{Km} / \mathrm{h})$ & $0.525^{*}$ \\
Max Humidity & $0.533^{*}$ & Mean Wind Speed $(\mathrm{Km} / \mathrm{h})$ & $0.583^{*}$ \\
Mean Humidity & $0.65^{* *}$ & Max Gust Speed $(\mathrm{Km} / \mathrm{h})$ & 0.182 \\
Min Humidity & $0.642^{* *}$ & Cloud Cover & $0.433^{*}$ \\
Max Sea Level Pressure $(\mathrm{hPa})$ & $-0.644^{* *}$ & Wind Direction Degrees & $0.516^{*}$ \\
\hline
\end{tabular}

${ }^{*}$ P-value $<0.05,{ }^{* *}$ P-value $<0.0001$.

and urbanization cause crowding, poverty, poor infrastructure and sanitation. All these features are conducive for the proliferation of mosquitoes.

We found temperature and humidity had a significant influence on malaria cases. This finding is consistent with other studies in which temperature is considered to be the precipitating factor for the Anopheles mosquito. ${ }^{15,16}$ In the Guangzhou area of China, rise in temperature and relative humidity has been shown to have a positive association with malaria incidence. ${ }^{17}$ Kipruto et al. established that rainfall had the most dominant cross correlation with malaria cases in riverine, highlands and lowlands regions and along with temperatures in highland and riverine contributed to variations in malaria incidence. ${ }^{18}$ Meanwhile, studies in Korea found sunshine to be positively associated with malaria incidence. ${ }^{19}$

In our study, one-unit increase in humidity of the previous month led to higher malaria cases in the incident month. This correlation of temperature and one month lag period with the monthly incidence of malaria cases was also observed in a study conducted over 12 years in the Shuchen county of China. ${ }^{20}$ Kipruto et al. also associated with a two month lag for rainfall in riverine, highlands and lowlands and up to one month for increase in temperature. ${ }^{18}$ The lag period in our case of one month compared with 0-4 months in other studies may be explained by the vector need for a fertile environment for its survival until it matures ${ }^{21}$ which may be geographically variable between these studies.
A study conducted in Peshawar, Pakistan had a total of 411 diagnosed malaria cases. Almost a third $(32.60 \%)$ presented in the autumn (falciparum $=66.42 \%$ ), $9 \%$ in winter (falciparum $=67.6 \%), 18.5 \%$ in spring (vivax $=93.4 \%$ ) and $40 \%$ in summer (vivax $=89.6 \%$ ). The authors concluded that malaria showed a highly significant pattern in different seasons of the year such that P. falciparum and P. vivax malaria reached their highest frequency in autumn and winter seasons and in spring and summer seasons respectively. ${ }^{22}$ The data on species correlation to seasonality could not be assessed in our study, due to half the data being missing. However, of those which were mentioned vivax was the predominant specie, which correlates with the 2018 world malaria report's statistics for Pakistan. ${ }^{3}$

The decline noted in our study in 2015 is as per the World Report for Pakistan. ${ }^{3}$ This may be attributed to it being the hottest year in the past 10 years in Karachi as seen in our study and evidence that temperature change have altered vector behavior. ${ }^{1,14}$ This may influence incidence apart from the other measures taken for vector control. By understanding the seasonality of malaria parasite, it is easier to prepare and implement malaria control measures. The preparation should be done well ahead of the peak transmission period by targeting mosquito and infected people simultaneously. The findings of this study provide preliminary information that can be useful to develop malaria early warning system. 


\section{CONCLUSION}

The incidence of malaria presenting to TIH has risen over recent years and significant seasonal variations in Karachi particularly temperature and humidity, has contributed to this.

Source of funding: None.

Conflict of interest: None.

\section{REFERENCES}

1. World Health Organization (WHO). Vector-borne diseases 2017 [updated 31 October 2017; cited 2019 19-Apr-2019]. Available from: https://www.who.int/en/news-room/ fact-sheets/detail/vector-borne-diseases.

2. World Health Organization (WHO). World malaria report 2015: World Health Organization; 2016.

3. World Health Organization (WHO). World malaria report 2018: World Health Organization; 2018.

4. Centers for Disease Control and Prevention (CDC). Anopheles Mosquitoes 2018 [updated November 14, 2018; cited 2019 19-Apr-2019]. Available from: https:/ / www.cdc. gov/malaria/about/biology/\#tabs-1-5.

5. Amerasinghe FP, Mukhtar M, Herrel N. Keys to the Anopheline mosquitoes (Diptera: Culicidae) of Pakistan. J Med Entomol. 2002;39(1):28-35. doi: 10.1603/0022-2585-39.1.28

6. Herrel N, Amerasinghe FP, Ensink J, Mukhtar M, van der Hoek W, Konradsen F. Breeding of Anopheles mosquitoes in irrigated areas of South Punjab, Pakistan. Med Vet Entomol. 2001;15(3):236-248. doi: 10.1046/j.0269-283x.2001.00312.x

7. Kasper DL, Fauci AS, Fauci A. Harrison's infectious diseases: Mcgraw-Hill medical; 2010.

8. Pampana E. A textbook of malaria eradication. 2 ed: London: Oxford University Press.; 1969.

9. Dhiman R, Bhattacharjee S, Adak T, Subbarao S, editors. Impact of climate change on malaria in India with emphasis on selected sites. Proceedings of the Workshop on Water Resources, Coastal Zones and Human Health held at Indian Institute of Technology, Delhi, New Delhi; 2003.

10. Khan AS. Sindh population surges by $81.5 \%$, households by 83.9\%. The News International. 2019 Fri Apr 19, 2019.

11. Specialists in Cultural A, Incentive Tours, Treks \& Safaris.,. Climate. Available from: http:/ / www.gandharatrails.com/ climate.html.

12. Web Desk. Extreme heat slaps Karachi - Hottest day in 10 years! The News Tribe. 2015 June 20, 2015.
13. Heatwave in Pakistan's Sindh province leaves 224 dead. BBC. 201522 June 2015.

14. Anwar F. Karachi city climate change-adaptation strategy a roadmap. J Res Archit Plan. 2012;11(1).

15. Thomson MC, Mason SJ, Phindela T, Connor SJ. Use of rainfall and sea surface temperature monitoring for malaria early warning in Botswana. Am J Trop Med Hyg. 2005;73(1):214-221. doi: 10.4269/ajtmh.2005.73.214.

16. Obsomer V, Dufrene $M$, Defourny $P$, Coosemans $M$. Anopheles species associations in Southeast Asia: indicator species and environmental influences. Parasit Vectors. 2013;6(1):136. doi: 10.1186/1756-3305-6-136

17. Li T, Yang Z, Wang M. Temperature, relative humidity and sunshine may be the effective predictors for occurrence of malaria in Guangzhou, southern China, 2006-2012. J Parasites vectors. 2013;6(1):155.

18. Kipruto EK, Ochieng AO, Anyona DN, Mbalanya M, Mutua EN, Onguru D, et al. Effect of climatic variability on malaria trends in Baringo County, Kenya. Malar J. 2017;16(1):220. doi: 10.1186/s12936-017-1848-2

19. Antonio-Nkondjio C, Simard F, Awono-Ambene $P$, Ngassam P, Toto JC, Tchuinkam T, et al. Malaria vectors and urbanization in the equatorial forest region of south Cameroon. Trans R Soc Trop Med Hyg. 2005;99(5):347-354. doi: 10.1016/j.trstmh.2004.07.003

20. Bi P, Tong S, Donald K, Parton KA, Ni J. Climatic variables and transmission of malaria: a 12-year data analysis in Shuchen County, China. Public Health Rep. 2003;118(1):6571. doi: $10.1093 / \mathrm{phr} / 118.1 .65$

21. Gunda R, Chimbari MJ, Shamu S, Sartorius B, Mukaratirwa SJMj. Malaria incidence trends and their association with climatic variables in rural Gwanda, Zimbabwe, 2005-2015. 2017;16(1):393.

22. Jamil S, Khan MN. Seasonal variations of vivax and falciparum malaria: An observation at a tertiary care hospital. J Ayub Med Coll Abbottabad. 2012;24(1):93-95.

\section{Author`s Contribution:}

FH: Conceived the idea, designed the proposal, writing \& editing of manuscript.

SI: Statistical analysis, results write-up, formatting \& editing of manuscript.

AN: Data collection, literature review and manuscript writing.

SR: Manuscript writing. 